\title{
Dose rates evaluation of HiPER facility
}

\author{
Rafael Juárez ${ }^{3 *}$, Javier Sanz ${ }^{\text {ab }}$, José M. Perlado ${ }^{3}$, Bruno Le Garree' \\ ${ }^{1}$ Instituto de Fusión Nuclear/UPM, Calle José Gutiérrez Abascal 2, Madrid, Spaín \\ ${ }^{\mathrm{b}}$ Dept. Ingeniería Energética UNED, Madrid, Spaín \\ ${ }^{\mathrm{c}}$ CEA-CESTA, Le Barp, France
}

\section{A R T I C LE I N F O}

Article history:

Available online $\mathrm{xxx}$

Keywords:

Prompt dose

Residual dose

Neutrón activation

Radiation shielding

HiPER project

\begin{abstract}
A B S T R A C T
During the operation of the HiPER first engineering facility, up to $1.2 \times 10^{5} \mathrm{MJ} / \mathrm{yr}$ of fusión neutrons yields are foreseen. This irradiation level could be distributed in $100 \mathrm{MJ}$ detonations, accounting up to 100 detonations in a single burst, with $10 \mathrm{~Hz}$ repetition rate. A burst would take place every month. The dose rates are computed and different concrete shields are evaluated within the target bay. During the operation of the facility the entrance is forbidden inside the bioshield. Between bursts, manual maintenance might be performed inside the bioshield but outside the final optics assembly (FOA) shield. Inside the FOA shield the residual dose rates are so high that only remote maintenance is allowed. The FOA shield reduces the delivered dose rate to optics in a factor of 30.3 .
\end{abstract}

(C) 2011 Elsevier B.V. All rights reserved.

\section{Introduction}

The HiPER phase 4 engineering facility irradiation scenario is not still decided.The most demanding one, up to the moment, has been thought to consist of $1.2 \times 10^{5} \mathrm{MJ}$ of neutrón yield per year. The D-T detonations could achieve 100MJ of fusión (14.1 MeV peaked distribution) neutrón yield. Distributed in bursts, up to 100 detonations could take place in an only sequence, with a repetition rate of $10 \mathrm{~Hz}$. A burst could be performed every month or less.

This high neutrón yield makes necessary the study of the radiological implications of the operation of the facility. The workers are exposed to neutrón and gamma yields. The dose rates are compared to the recommendations given in ICRP74 [1], 20mSv/yr for workers (10 jiSv/h distributed in $8 \mathrm{~h}$ of work during 50 weeks).

The final optics assembly (FOA) is one of the most sensitive parts of the facility to the radiation. Even when the shields are designed to protect the workers, it is mandatory to compute their effect on the dose rate delivered to the FOA for further considerations.

The design studied in this paper consists of a reaction chamber, 48 beam tubes, 48 renewable lenses and 48 FOA assemblies of 6 optical elements each one [2]. To accomplish a correct operation of facility, four concrete shields have been added and evaluated in different parts of the design.

During the operation, we have computed the absorbed dose rate in the FOA and the ambient dose equivalent (ADE) to workers inside the facility. Then, considering the resulting activation of the components, we have calculated the $\mathrm{ADE}$ delivered to the workers between bursts. Dose rates during operation and between bursts are computed as independent and they are summed because the working plan is not defined and total exposures cannot be computed.

With this information we have evaluated the different shields and made recommendations on the maintenance procedures. If necessary, further studies would be carried out on FOA specifically.

\section{Design proposal}

This study is focused on the target bay. It has to be understood as that part of the reactor building where the radiation level demands special attention. It is considered to be the rooms inside the bioshield.

\subsection{Basic components}

The reaction chamber is the closest component to the detonations. A $10 \mathrm{~cm}$ thick, $10 \mathrm{~m}$ of inner diameter spherical shell, it is assumed to be built of stainless steel SS304L [3] because its good equilibrium between neutrón activation, thermomechanical properties and economics. There would be 48 beam penetrations in the reaction chamber, distributed into six rings, with the angular distribution specified in Table 1 . There are only three rings described since the lower part of the chamber is a specular reflection on the plañe $\mathrm{z}=0$, and rotated $23.36^{\circ}$. The penetrations are $40 \mathrm{~cm}$ radius rims. Diagnostics penetrations are not considered in this study.

In order to accomplish the inertial laser-driven fusión D-T reactions, the láser should be entered into the chamber from the láser bay. The láser beams are transported inside the beam tubes, where 
Table 1

Number of rims per ring and angular coordinates of one rim. The rest of the rims are distributed uniformly inthe ring.

$\begin{array}{rrr}\boldsymbol{N}, & \mathbf{e},\left(^{\circ}\right) & <p_{i}\left(.^{\circ}\right) \\ 4 & 21.23 & 0.00 \\ 8 & 47.03 & 23.36 \\ 12 & 74.95 & 29.83\end{array}$

vacuum is maintained. The beam tubes have a squared section of $1 \mathrm{~m}$ long side. The tubes wall thickness is $1 \mathrm{~cm}$, and they are assumed to be built of SS304L stainless steel.

The beam tubes host the optical elements, which are built of fused silica SÍO2. There are two optical groups. From the center of the reaction chamber, the first group is a 48 renewable lenses assembly, devoted to focus the beam before entering the reaction chamber through the rims. These lenses are $75 \mathrm{~cm}$ side squares with $5 \mathrm{~cm}$ of thickness. This group will get damaged quickly, so it is expected to be removed frequently. They are called the renewable lenses.

The second optical group is made up of six different elements with its own function (frequency converters, mirrors, and focusing lenses). The thick of these elements varíes from 1 to $5 \mathrm{~cm}$. They are also $75 \mathrm{~cm}$ side squares. This group is called the FOA, and it is a very sensitive part of the reactor to be protected from the radiation $[4,5]$. Although this study is not committed to protect this optics, the absorbed dose rates are computed in FOA during the operation.

\subsection{Shields}

To protect the facility against radiation and maintain the dose limits to workers cióse to the recommendations, several concrete shields are added. Those are a prospective proposal for further improvements. Concrete has been chosen for being a standard shielding material in the presence of neutrons and gammas.

As may be seen in Fig. 1, there are four types of concrete shields. From the center of the reaction chamber, they are the chamber shield, the pinhole shield, the FOA shield and the bioshield.

The reaction chamber shield is a $40 \mathrm{~cm}$ thick of borated gunite concrete spherical shell, adopted from NIF design [6]. This shield is pursued to reduce the dose rate between bursts due to the acti-

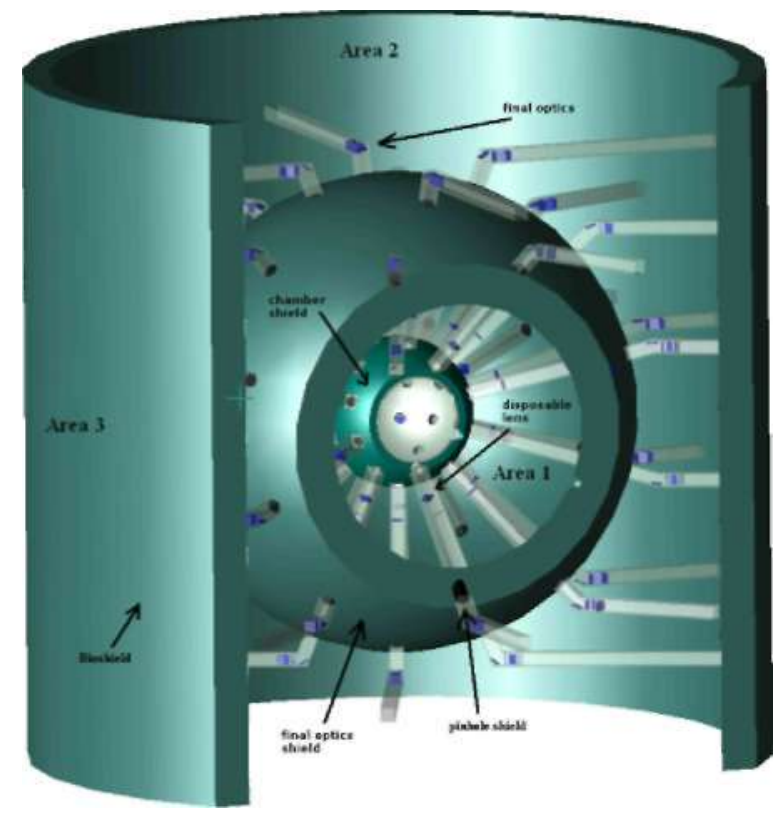

Fig. 1. HiPER design to study neutronics and activation, performed with MCAM. vation of the chamber as well as reducing the total amount of neutrons, which actívate the whole facility.

From 15 to $17 \mathrm{~m}$ from the center of the reaction chamber, there is a spherical shell shield, called the FOA shield. Despite its ñame, it has consequences in many aspects: it protects the FOA against high doses in operation, helps to reduce the total dose rates delivered outside the target bay and reduces the dose rates between bursts after it. This shield creates two different áreas inside the target bay and allows certain manual maintenance in the external one.

It has been modeled as a spherical shell because this geometry improves the efficiency of the Monte Cario modeling and simulation. In order to explore different thicknesses, it was thought to be the best approach. Once the shield thickness is decided according to dose limit criteria, this shield will adopt another form, with better constructive and structural properties.

The rims, the beam tubes and the penetrations in FOA shield represent a free way for the neutrons to spread out, and in order to protect the FOA, there is a cylindrical shield placed inside the beam tubes. As the beam travels, it adopts a variable focusing profile. Where the beam is focused (mínimum spot size), at $16 \mathrm{~m}$ from the center of the chamber, the center of this shield is placed, presenting a $5 \mathrm{~mm}$ radius pinhole to allow the beam to pass through. It is a $2 \mathrm{~m}$ long, $1 \mathrm{~m}$ diameter cylinder, which lies in the final optic shield, in the transition between one tube and its prolongation after the final optic shield. Other materials for the pinhole shield different to concrete will be tested in further studies.

Finally, as high neutrón yields are expected, it has been added a $2 \mathrm{~m}$ thick bioshield at $25 \mathrm{~m}$ from the center of the reaction chamber. Its aim is to definitely sepárate the target bay from the rest of the facility.

Inside the target bay there are two different rooms, called área 1 and área 2; (see Fig. 1) the two first meters of air outside the bioshield, i.e., the exterior of the target bay, are referred as the área 3.

The composition of no-borated concrete assumed in this study for the FOA shield, pinhole shield and bioshield is taken from [7].

\section{Methodology and assumptions}

\subsection{Methodology}

To perform this study we have used the following methodology. The first step has been to design the geometry of the facility using MCAM [8] code. This is a tool conceived to draw and transíate complex geometries into Monte Cario transport codes.

Once the geometry was decided [2], with MCAM it was generated an input file valid for MCNPX [9] transport code. The resulting neutrons transport from the detonations was performed with MCNPX and cross-section libraries lal 50n, endf60 and end192, depending on the availability for every isotope. The absorbed dose rate in the FOA was calculated directly with MCNPX. With the flux-to-dose conversión coefficients [10] for ambient dose equivalent, the dose rates to workers were calculated. Extended vitamin-J

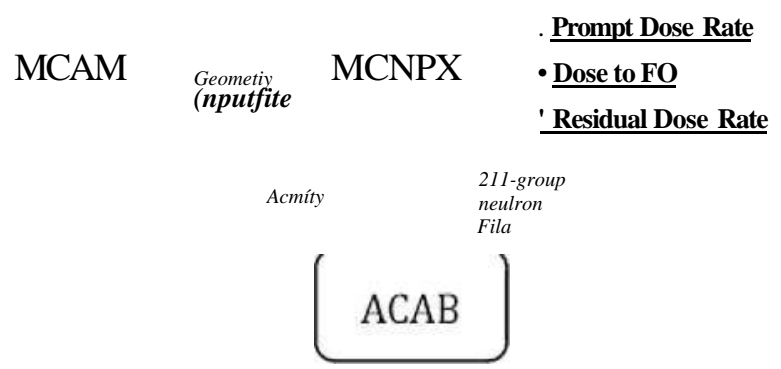

Fig. 2. Scheme of computational methodology. 


\section{Residual dose rate between burst}

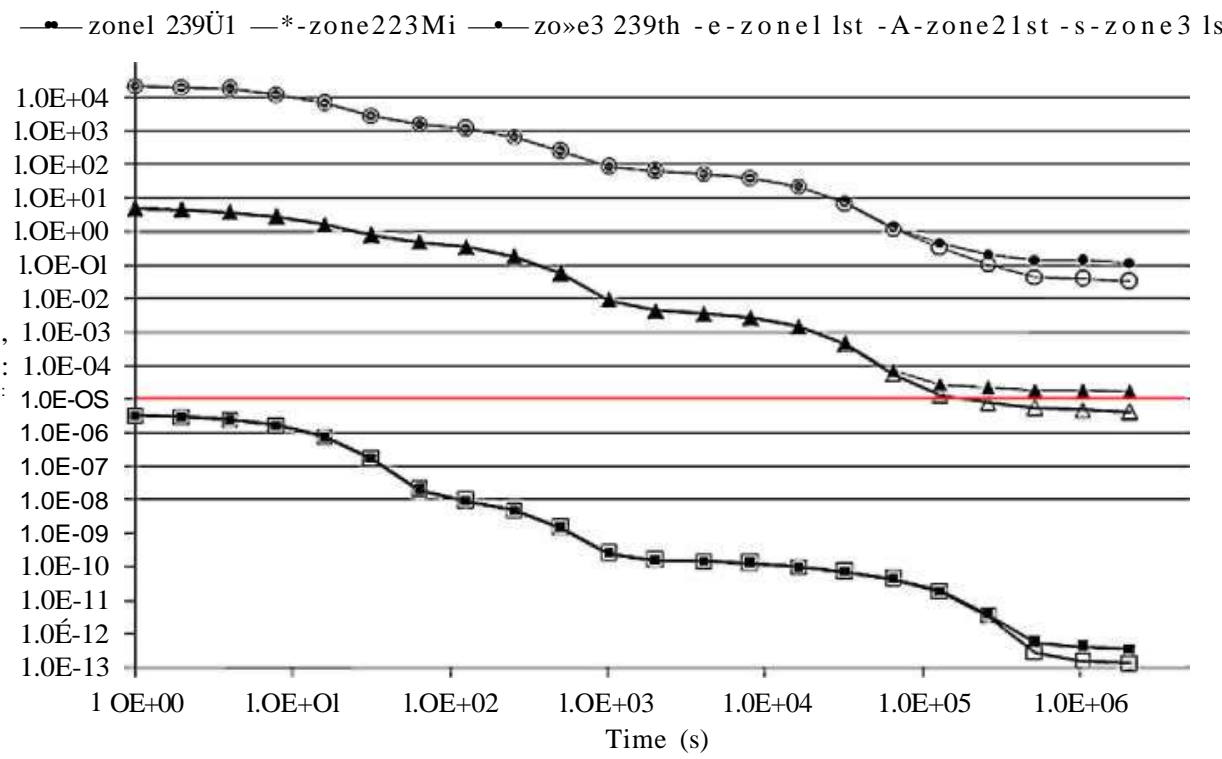

Fig. 3. Residual dose rate in the three different áreas afterthe 1st and the 239th burst. The red line stands for the hands-on maintenance, 10 |xSv/h. (For interpretation of the references to color in this figure legend, the reader is referred to the web versión of the article.)

group structure neutrón fluxes in every component of the facility were extracted to compute the resulting activation.

With ACAB code [ 11] and the EAF activation libraries [12], it was then computed the activation derived from the exact pulsed regime ofthe reactor for every component ofthe facility. With MCNPXthe resulting decay gammas were transported through the target bay and the residual dose rates were computed, again with the ICRP coefficients.

\subsection{Assumptions}

The source neutrons have been assumed to born according to a direct drive inertial fusión detonation spectrum [13].

With regards to $\mathrm{ADE}$ to workers during the operation, there is no preferred position inside the target bay, as long as there is no foreseen mandatory presence of workers. So it makes no sense measuring specific places, and the average gives a reasonable estímate. Thus, the ADE to workers is averaged over any ofthe three possible áreas ofthe facility (see Fig. 1).
Concerning with the dose rates between bursts, as there is no specific procedure for the maintenance up to now, the general idea of what happens in every área is given by the average $\mathrm{ADE}$ in that área.

Outside the target bay, the ADE is averaged in the first $2 \mathrm{~m}$ of air, representing the closest position of a person to the bioshield.

It has to be kept in mind that the average dose rates represent no more than estimates. In order to compute the accurate dose rate received by the workers it is necessary to know the whole activity, the place where it is carried out and its duration.

The absorbed dose rate to the FOA has been averaged in the whole group of lenses in order to increase the efficiency ofthe simulations. So, the results are average dose in all the lenses. When further decisions were made on the design, a more precise calculation will be carried out in every single component (Fig. 2).

With regards to the composition of the different materials, reasonable concentrations of impurities have been assumed for SS304L [3] and concretes [6,7]. The SíO2 has been considered to be puré.

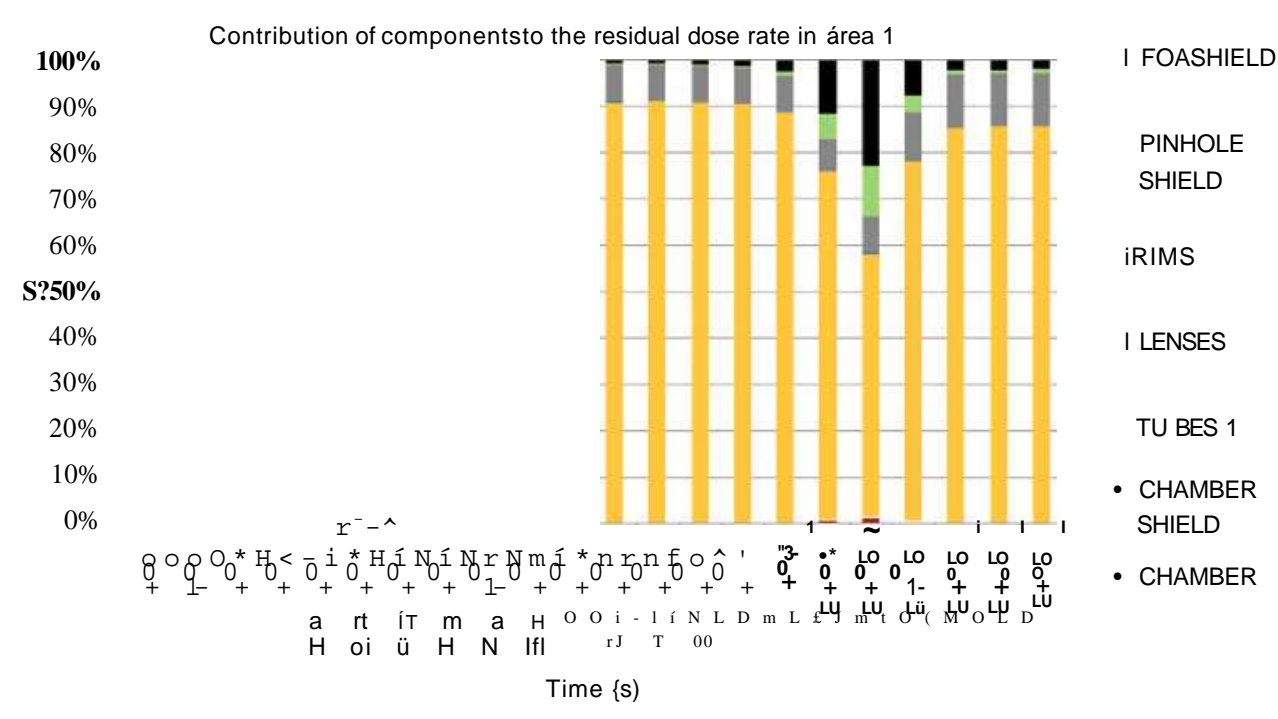

Fig. 4. Contribution of different components to the residual dose rate in área 1. 


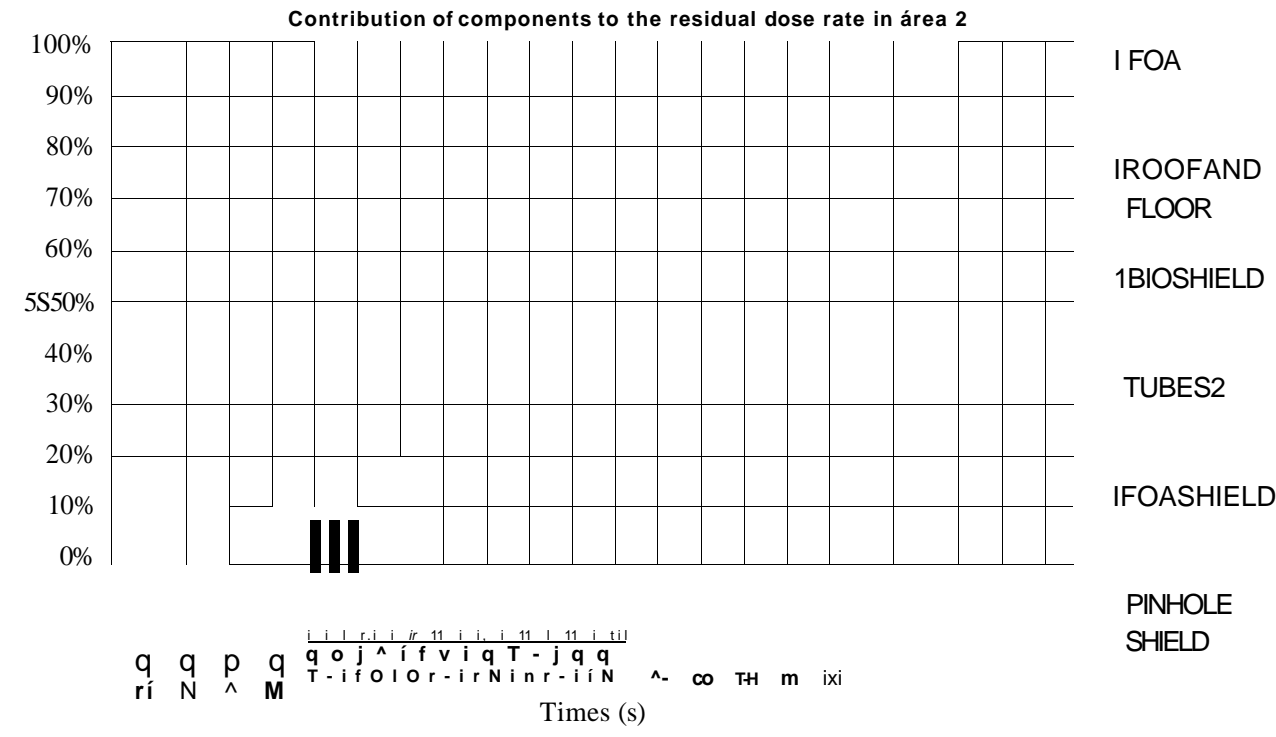

Fig. 5. Contribution of different components to the residual dose rate in área 2.

\section{Results and analyses}

The presence of the FOA shield affects dramatically to the absorbed dose rate in this group of lenses during operation. We have computed the absorbed dose rate in the FOA every year considering the absence and presence of the FOA shield, being present in both cases the pinhole shield.

The results, in Table 2 show that this shield reduces in a factor of 30.3 the total dose delivered to these components. If those levéis of irradiation result to be unacceptable in the FOA, further protection will be added.

The ADEs to workers (Table 3) indícate that entrance is not allowed área 1 and área 2 during the operation of the reactor. The exterior of the target bay fulfills the conditioning of representing a dose rate below the limit to workers.

The high radiation level present inside área 1 , and even in área 2 , makes necessary to carefully design and protect the electronics which could be present in these áreas during the operation of the reactor.

The time evolution between bursts of the ADE to workers is depicted in Fig. 3. The cumulative effect of long-live radioisotopes makes the residual dose rate to increase in up to a factor of 4 between the first and the last burst.

The contributions between bursts of every activated component to the total $\mathrm{ADE}$ to workers in áreas 1 and 2 are depicted in Figs. 4 and 5. The residual dose rate in área 3 is exclusively due to the activation of the bioshield.

Table 2

Prompt dose rate delivered to the FOA considering the absence and presence of the final optic shield.

\begin{tabular}{lcll}
\hline & No-shield $(\mathrm{Gy} / \mathrm{yr})$ & Shielded $(\mathrm{Gy} / \mathrm{yr})$ & Relation \\
\hline Neutrons & 571 & 34.1 & 16.7 \\
Gamma & 891 & 14.2 & 62.7 \\
Total & 1460 & 48.2 & 30.3 \\
\hline
\end{tabular}

Table 3

Prompt dose rates to workers averaged in áreas 1, 2 and 3.

\begin{tabular}{llcl}
\hline & Área $1(\mathrm{~Sv} / \mathrm{yr})$ & Área $2(\mathrm{~Sv} / \mathrm{yr})$ & Área $3(\mathrm{~Sv} / \mathrm{yr})$ \\
\hline Neutrons & $3.46 \times 10^{5}$ & 32.9 & $1.69 \times 10$ \\
Gamma & $8.70 \times 10^{3}$ & 0.63 & $1.88 \times 10$ \\
Total & $3.55 \times 10^{5}$ & 32.6 & $2.05 \times 10$ \\
\hline
\end{tabular}

The entrance in área 1 is forbidden also between bursts. There are several activated components, which represent an $\mathrm{ADE}$ much higher than $10 \mathrm{jiSv} / \mathrm{h}$ during the whole month. Thus, in case that maintenance was necessary, robotics would be essential. From $1 \mathrm{~h}$ after the shutdown to the next burst, the main contributors to the dose rate are the beam tubes, the optical shield and the rims. However, due to the high dose rate, it is not worthwhile to try to reduce it.

It is not the case for the área 2. Around $36 \mathrm{~h}$ after the first burst, the $\mathrm{ADE}$ falls below the $10 \mid \mathrm{jiSv} / \mathrm{h}$ limit, and workers could enter $8 \mathrm{~h}$ per day. However, two facts must be kept in mind. The first one is that the average dose is an estímate, and in order to make decisions on the maintenance, it is necessary to know the activity to be carried out, the position, and the exposure time. The second fact is that even when workers could not stand inside the área 2 for $8 \mathrm{~h}$ per day, as bursts happen, collective dose planning could allow manual maintenance.

Another alternative is to act on the second beam tubes, as they are the main responsible for this dose rate after some minutes. Different strategies are: to shield the tubes against neutrons, to shield the workers against the gamma that they emit or choosing another material with lower activation at these time scales.

The área 3 is below the recommend limit for the public and the workers, so, it stands for the exterior of the target bay.

\section{Conclusions}

The shielding requirements for a preliminary HiPER design have been analyzed.

The absorbed dose rate during operation in the FOA reaches valúes of $1460 \mathrm{~Sv} / \mathrm{yr}$ in the absence of FOA shield. The FOA shield reduces this quantity to $48.2 \mathrm{~Sv} / \mathrm{yr}$, a reduction of a factor 30.3 .

During the operation, workers are not allowed to enter in áreas 1 and 2, while the área 3 fulfills the recommendations to workers regarding with dose rates.

Maintenance inside área 1 must be strictly remote. Inside the área 2 , it is expected manual maintenance after some considerations, planning and likely modifications of the design. In área 3, manual maintenance is recommended. 


\section{Acknowledgements}

This work has been performed for HiPER: European High Power Láser Energy Research Facility (Preparatory Phase Study). The authors gratefully acknowledge the support of the funding agencies in undertaking this work (EC FP7 project number 211737): EC, European Commission, MSMT, Ministry of Education, Youth and Sports of the Czech Republic and STFC, Science and Technology Facilities Council of the United Kingdom.

The authors thank to Bruno Le Garree from CEA for providing the information of the preliminary design of the HiPER reactor and helpful and fluid communication during the development of this study.

\section{References}

[11 ICRP publication, 74,1996.

[2] B. Le Garree, Prívate communication, 2010.

[3] J. Sanz, O. Cabellos, S. Reyes, Fusión Eng. Des. 75-79 (2005) 1157-1161.

[4] J.F. Latkowski, A. Kubota, MJ. Caturla, S.N. Dixit, J.A. Speth, et al., Fusión Sci. Technol. 43 (2003).

[5[ C.D. Marshall, J.A. Speth, S.A. Payne, J. Non-Cryst. Solids 212 (1997) 59-73.

[6[ J.F. Latkowski, Fusión Technol. 39 (2001) 956-959.

[7[ J.F. Latkowski, J. Sanz, UCRL-JC-133680,1999.

[8[ Y. Wu, FDS Team, Fusión Eng. Des. 84 (2009) 1987-1992.

[9[ D.B. Pelowitz, MCNPX User's Manual, LA-CP-05-0369 (2005) and extensions.

[10[ ICRP publication 60, An a ICRP 21 (1990) 1-3.

[ 11 [ J. Sanz, et al., ACAB User's Manual v.2008. NEA-1839.

[12[ R-A. Forrest, EAF-2007 transport libraries, UKAEAFUS 538, 2007.

[13] J. Perkins, Prívate communication. 